\title{
Phytochemical profile, acute dermal toxicity and wound healing activity of Guettarda calyptrata A. Rich
}

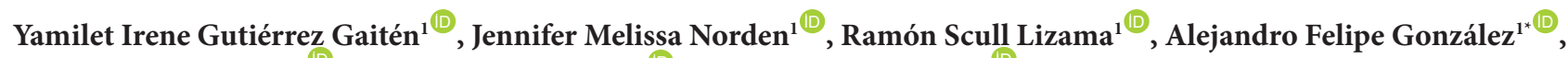 \\ Loida Oruña Sánchez ${ }^{2}{ }^{\mathbb{D}}$, Alen Nils Baeza Fonte ${ }^{\mathbb{1}}$, Zuleira Ocanto Torres $^{4}$ \\ ${ }^{1}$ Department of Pharmacy, Institute of Pharmacy and Food, University of Havana, Havana, Cuba \\ ${ }^{2}$ Department of Research and Teaching, Institute of Oncology and Radiology, Havana, Cuba \\ ${ }^{3}$ Laboratory for the Characterization of the Structure of Substances, Institute of Materials Science and Technology, University of Havana, Havana, Cuba \\ ${ }^{4}$ Department of Clinical Chemistry-Microbiology. Immunoassay Center, Havana, Cuba
}

\section{A R T I C L E I N F O}

Article Type:

Original Article

\section{Article History:}

Received: 17 September 2020

Accepted: 11 November 2020

\section{Keywords:}

Guettarda calyptrata

Hydroalcoholic extract

Phytochemistry

Rutin

Quercetin

Toxicology

Healing activity

\begin{abstract}
A B S T R A C T
Introduction: The leaves and barks of Guettarda calyptrata have been attributed to the property of healing wounds on the skin and mucous membranes. However, the scientific information about the phytochemical composition and biological properties is scarce. This research evaluates the chemical composition, dermal safety, and wound healing properties of a hydroalcoholic extract of G. calyptrata.

Methods: Hydroalcoholic extract of G. calyptrata was obtained from leaves. The phytochemical profile was analyzed by phytochemical screening, thin layer chromatography, high performance liquid chromatography (HPLC), and quantification of phenols and flavonoids by Folin-Ciocalteu and aluminum chloride methods, respectively. An acute dermal toxicity test was performed in rats, and the healing activity was evaluated using the excision wound model at $100 \mathrm{mg} / \mathrm{kg}$ of the extracts. Statistical significance $(P<0.05)$ was determined by an analysis of variance followed by the Student-Newman-Keuls test.

Results: The presence of alkaloids, saponins, terpenoids, phenolic compounds, rutin, and quercetin flavonoids, among others, was suggested. The extract did not cause toxicity at the dose of $2000 \mathrm{mg} /$ $\mathrm{kg}$ and was able to reduce the size of the wounds during the seven days of the test, with a healing effect comparable to the silver sulfadiazine cream used as a positive control, favoring collagen deposition and re-epithelialization.

Conclusion: This work makes an important contribution to the chemical composition and provides the first findings on the efficacy in the healing of topical wounds, which justify the use of G. calyptrata in traditional Cuban medicine.
\end{abstract}

Implication for health policy/practice/research/medical education:

Guettarda calyptrata extract possesses significant would healing activity and absence of acute dermal toxicity. It might be used as a possible candidate for wound healing treatment.

Please cite this paper as: Gutiérrez Gaitén YI, Melissa Norden J, Scull Lizama R, Felipe González A, Oruña Sánchez L, Baeza Fonte AN, Ocanto Torres Z. Phytochemical profile, acute dermal toxicity and wound healing activity of Guettarda calyptrata A. Rich. J Herbmed Pharmacol. 2021;10(2):249-256. doi: 10.34172/jhp.2021.28.

\section{Introduction}

For centuries, natural substances, particularly plants, have been used to control and treat diseases and this has culminated in the discovery of the majority of modern pharmaceutical agents. It has been estimated that approximately over half of the pharmaceuticals in clinical use today are derived from natural products (1).

The traditional knowledge about medicinal plants is the first clinical evidence on efficacy of herbal medicine; however, scientific studies are necessary to corroborate the ethnobotanical information (2). On the other hand, medicinal plants have been recommended as potential source for the management and treatment of wounds due to the presence of various active phytoconstituents, but scientific evidence of their healing potential is insufficient $(3,4)$.

Guettarda calyptrata A. Rich. (Rubiaceae) is a shrub native to Cuba. The leaves and bark are traditionally used for healing wounds on the skin and mucous $(5,6)$. The scientific information about this specie is limited; until 
now, only the presence of phenols compounds and the antioxidant activity of the aqueous extract of the leaves have been reported (7). The lack of phytochemical and biological information to support the traditional use of this specie and their efficacy and security have motivated the present research which evaluates the chemical composition, dermal safety, and wound healing activity of a hydroalcoholic extract of G. calyptrata.

\section{Materials and Methods}

Plant material and preparation of the extracts

Leaves of G. calyptrata A. Rich. (Rubiaceae) were collected in January 2018 at coastal areas of the locality of Cojímar, Havana, Cuba $\left(23^{\circ} 09^{\prime} 47^{\prime \prime} \mathrm{N}-82^{\circ} 17^{\prime} 38^{\prime \prime} \mathrm{W}\right)$. The material was identified in the National Botanical Garden of Cuba, where a voucher specimen (HFC-089021) was deposited. The material was dried in an oven (AI-SET-DNE 600, Shanghai, China) at $40^{\circ} \mathrm{C}$ for four days and fragmented in a knife mill until the size of the particles was less than 2 $\mathrm{mm}$. Hydroalcoholic extracts was obtained by maceration with sporadic agitation at room temperature in the dark, during seven days. Five milliliters of $80 \%$ ethanol were used for each gram of dry plant material.

Chemical characterization of the extract

Phytochemical screening

The phytochemical screening was carried out through the assays of Dragendorff [alkaloids], Wagner [alkaloids], Baljet [lactones and coumarins], Liebermann-Burchard [triterpenes and steroids], Fehling [reducing sugars], foaming [saponins], ferric trichloride [polyphenols], ninhydrin [amino acids], Bornträger [anthraquinones], Kedde [cardiotonic glycosides] and Shinoda [flavonoids]. Color changes of the extracts by applying the mentioned reagents were observed (8).

\section{Thin layer chromatography (TLC) profile}

Aluminum-backed silica gel TLC plates F $254 \mathrm{~nm}$ (Merck, Germany) was used. Rutin and quercetin (98\% purity, Sigma-Aldrich) were used as standards. The chromatography was carried out using as mobile phase: n-butanol:acetic acid:water (65:25:10, v/v/v). The TLC plates were visualized under UV light at $254 \mathrm{~nm}$, revealed with iron chloride $\left(\mathrm{FeCl}_{3}\right)$ at $5 \%$ in physiological saline solution and aluminum chloride $\left(\mathrm{AlCl}_{3}\right)$ at $5 \%$ in methanol (Merck, Germany). Finally, TLC plates were sprayed with $5 \% \mathrm{H}_{2} \mathrm{SO}_{4}$ in ethanol and heated to approximately 105 ${ }^{\circ} \mathrm{C}$ until the appearance of spots or modification of the appearance of existing ones.

\section{High-performance liquid chromatography (HPLC) profile} One millilitre of extract was dried, re-dissolved in 10 $\mathrm{mL}$ of methanol (Merck) and filtered. An inertsil ODSSP column $(4.6 \times 250 \mathrm{~mm}, 5 \mu \mathrm{m})$ was used for the separation. $10 \mu \mathrm{L}$ of sample was injected in the equipment
(Shimadzu-2010, China) and running at flow of $1 \mathrm{~mL} /$ min. UV visible detector at $255 \mathrm{~nm}(200-600 \mathrm{~nm})$ was used. The mobile phase consisted of formic acid $0.1 \%$ in water (A) and acetonitrile (B). The gradient used was 0-5 minutes, $80-20 \% \mathrm{~B}$; $5-10$ minutes, $60-40 \% \mathrm{~B}$; 10 20 minutes, $60-40 \%$ B; 20-35 minutes, $10-90 \%$ B; 35 50 minutes, $10-90 \%$ B; $50-60$ minutes, $80-20 \%$ B. Rutin and quercetin ( $98 \%$ purity, Sigma-Aldrich) were used as standards at $0,05 \mathrm{mg} / \mathrm{mL}$.

\section{Content of total phenols and flavonoids}

Content of total phenols was determined by the FolinCiocalteu method (9) and gallic acid (Sigma-Aldrich) was used as standard at concentrations of 10, 20, 30, 40 and 50 $\mathrm{mg} / \mathrm{mL}$. On the other hand, the content of total flavonoids was carried out by the colorimetric method using aluminum chloride (10) and quercetin (Sigma-Aldrich) was used as the reference substance at the concentrations of $10,15,25,50$ and $100 \mu \mathrm{g} / \mathrm{mL}$. In each case, a linear calibration curve was constructed with absorbance measured with a spectrophotometer Rayleigh UV-1601 (Beijing, China) at $765 \mathrm{~nm}$ and $415 \mathrm{~nm}$, respectively. The total phenol and flavonoid contents were determined with respect to the reference calibration curves.

\section{Acute dermal toxicity}

The test was conducted according to the OECD draft guideline number 434 (11). Albino Wistar rats (180 and $200 \mathrm{~g}$ ) from the Center for Laboratory Animal Production (Cuba) were used. In the experiment we worked with two groups of three animals (males and females) to which the extract was administered, dermally at a single dose of 2000 $\mathrm{mg} / \mathrm{kg}$ of body weight (b.w) and left in contact with the skin 24 hours (in an area of $10 \%$ of the body surface on the previously shaved back).

Animals were observed immediately after dosing at least once during the first 30 minutes, periodically during the first 24 hours, with special attention given during the first 4 hours and daily thereafter, for a total of 14 days. Observations included skin rashes or dermatitis, changes in skin and fur, eyes, mucous membranes, also respiratory, circulatory, autonomic and central nervous systems, somatomotor activity and behavior pattern, tremors, convulsions, salivation, diarrhea, lethargy, sleep and coma. Various organs were examined (lungs, heart, spleen, kidney and stomach). The body weight of the animal was recorded at the beginning of the experiment, at seven and 14 days of the test.

\section{Wound healing activity}

\section{Animal model}

The excisional wound model was used on the back of the rat (12). Male Wistar albino rats (286 and $310 \mathrm{~g}$ ) from the Center for the Production of Laboratory Animals (Cuba) were used. Three groups of five animals each were made: 
group I- control without treatment, group II-positive control - silver sulfadiazine $25 \mathrm{mg} / \mathrm{kg}$ b.w ("Roberto Escudero" Pharmaceutical Laboratory, Cuba) and group III- hydroalcoholic extract of G. calyptrata $100 \mathrm{mg} / \mathrm{kg}$ b.w. All products were administered topically every 24 hours. The rats were depilated in the dorsal scapular region, approximately $10 \%$ of the body surface. The wounds were made with a $10 \mathrm{~mm}$ diameter punch. To avoid the pain and suffering of the animals, they were anesthetized with Pentobarbital sodium $40 \mathrm{mg} / \mathrm{kg}$ b.w by intraperitoneal route.

The observations were made for seven days, the size of the wounds $(\mathrm{mm})$ was measured (with a ruler) and the body weight of the animals ( $g$ ) was determined, starting from the first day of testing.

\section{Histopathological evaluation}

After the seventh observation, the animals were sacrificed, and scar tissue samples were taken for histopathological evaluation. Skin fragments were taken from the wounds, fixed in $10 \%$ buffered neutral formalin (Sigma-Aldrich) to later be processed in paraffin and finally cut on a Kedee hand microtome (model KD-202A, China). The deparaffinized sections (between 5 and $8 \mu \mathrm{m}$ ) were stained with hematoxylin and eosin (Sigma-Aldrich) (13). Histological observations were made through an Olympus CX-21LED (Japan) optical microscope (10X and 20X lenses) coupled to an Olympus (Japan) digital camera. To evaluate the results, the evolution of epithelial migration was considered in the healing of open wounds in rats and dermal reconstitution $(12,14)$.

\section{Ethical consideration of biological assays}

The biological experiments were carried out following the provisions of the standard operating procedures in force at the Study Center for Biological Investigations and Evaluations of the Institute of Pharmacy and Food of the University of Havana (Cuba), approved by the ethics committee of the institution. The ethical principles that govern animal experimentation were respected, guaranteeing their well-being and protection, both for human sensitivity to animal suffering, and for guaranteeing the validity of the results obtained. International bioethics and biosafety standards were met (15).

\section{Statistical analysis}

The experiments were conducted in triplicates and the results were expressed as mean/standard deviation (SD). Statistical significance $(P<0.05)$ was determined by an analysis of variance followed by the Student-NewmanKeuls test using SPSS version 8.0 for Windows.

\section{Results}

Chemical characterization of the extracts In phytochemical analysis the presence of reducing sugars, coumarins, phenols, tannins, saponins, terpenoids, steroids, alkaloids and flavonoids was observed. In contrast, the assays for quinones and cardiotonic glycosides were negatives. The presence of rutin and quercetin was corroborated by TLC with the apparition of two spots at Rf 0.70 and 0.92 , similar to observed for the standards chromatographed (Figure 1).

The extract showed other fluorescent spots close to the point of application that confirms the presence of molecules with conjugated chromophore groups in their structure. The development with $\mathrm{FeCl}_{3}$ solution (Figure 1B) visualized blackish-green spots, suggesting phenolic compounds derived from catechol, as well as others of a reddish-brown color at the point of application, possibly glycosylated compounds. When sprayed with $\mathrm{AlCl}_{3}$ solution (Figure 1C), the standards spots and the like in the extract exhibited an intense yellow color characteristic of flavonoids. With $\mathrm{H}_{2} \mathrm{SO}_{4}$ solution and subsequent heating (Figure 1D), a good visualization of all spots was observed; the spots corresponding to the reference substances and those of Rf 0.71 and 0.90 display a typical yellow-orange color of flavonoids. Brown spots were also seen that could be related to glycosylated compounds and phenols in general.

The HPLC study was carried out for qualitative purposes, based on the results of the analysis by TLC. Chromatograms are presented in Figure 2. The control substances rutin (Figure 2A) and quercetin (Figure 2B) had retention times of 22.28 and 25.48 minutes, respectively. The extract (Figure 2C) showed a large number of chromatographic peaks that eluted before 22 minutes, associated with the most polar compounds of the extract, given the affinity with the polar mobile phase used. Other less polar compounds were observed with retention times between 40 and 50 minutes. In the interval from 22 to 26 minutes, two peaks of medium intensity were observed with retention times of 22.10 and 25.20 minutes, related to the two flavonoids tested (rutin and quercetin). The UV-
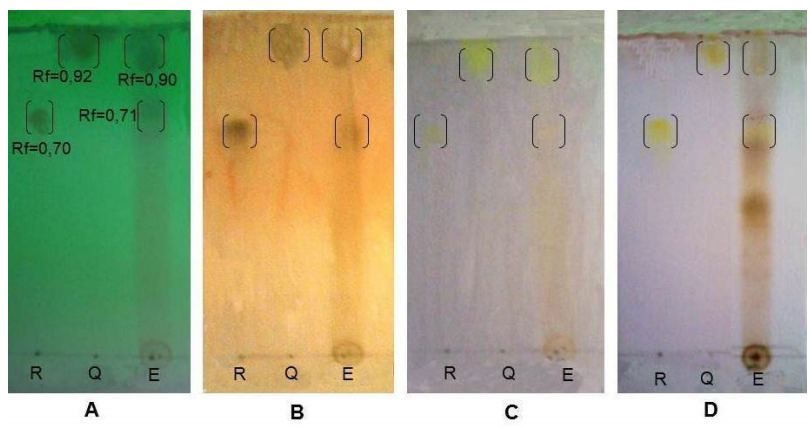

Figure 1. Chemical profile by Thin Layer Chromatography (TLC) of hydroalcoholic extract of Guettarda calyptrata. Aluminum-backed silica gel TLC plates. Mobile phase: n-butanol:acetic acid:water (65:25:10, v/v/v). (A): UV $254 \mathrm{~nm}$; (B): $\mathrm{FeCl}_{3}$ solution; (C): $\mathrm{AlCl}_{3}$ solution; (D): $\mathrm{H}_{2} \mathrm{SO}_{4}$ / heat; R: Rutin, Q: Quercetin; E: extract. 

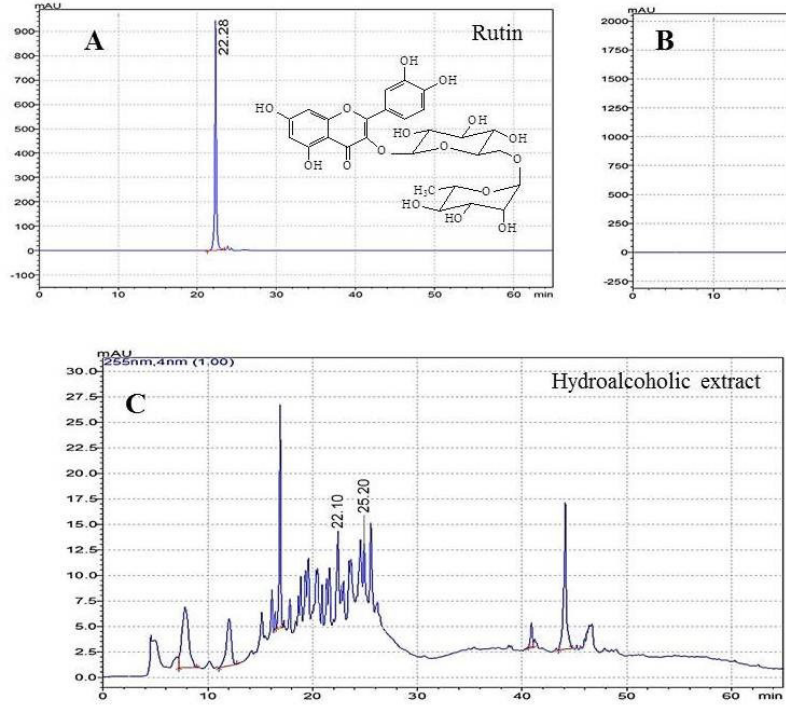

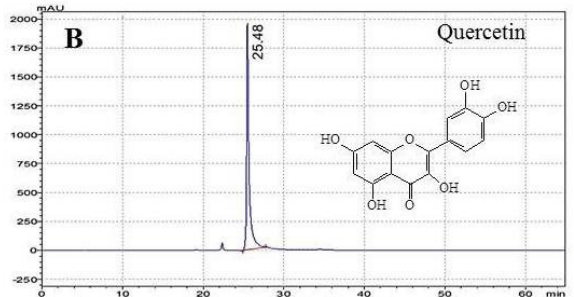

D
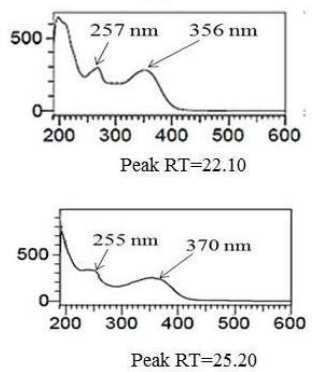

Figure 2. Chemical profile obtained by HPLC of hydroalcoholic extract of Guettarda calyptrata. A: quercetin chromatogram; B: rutin chromatogram; C: chromatogram of the hydroalcoholic extract; D: UV-visible spectra of rutin and quercetin peaks present in the extract.

visible spectrum (Figure 2D) confirmed the presence of these compounds.

Content of total phenols and flavonoids

The concentration of total phenols was $5.23 / 0.15 \mathrm{mg} /$ $\mathrm{mL}$ (mean/standard deviation) and it was estimated from a gallic acid calibration curve with the equation $\mathrm{Y}$ $=0.0123 \mathrm{X}+0.0376$ and a correlation coefficient $\left(\mathrm{R}^{2}\right)$ of 0.9997 . The total flavonoids were expressed as quercetin from the equation $\mathrm{Y}=0.0036 \mathrm{X}+0.0270$, with a correlation coefficient of 0.9995 , the value was $1.96 / 0.04 \mathrm{mg} / \mathrm{mL}$. In both determinations, the correlation coefficient was higher than 0.99 , indicating the good fit of the model equations to the experimental data.

\section{Acute dermal toxicity}

An acute dermal toxicity test was conducted, considering the traditional route of administration given to the species. Table 1 shows the average weights of the animals during the 14 days of study. Significant differences were found when comparing the body weight of the same group at the times evaluated. During the development of the trial there were no deaths, no clinical alterations in

Table 1. Variation in body weight $(\mathrm{g})$ of animals in the acute dermal toxicity test of the hydroalcoholic extract of Guettarda calyptrata

\begin{tabular}{lccc}
\hline \multirow{2}{*}{ Groups } & \multicolumn{3}{c}{ Average weight (g) } \\
\cline { 2 - 4 } & 1st day & 7th day & 14th day \\
\hline Females (I) & $202.0 / 8.0^{\mathrm{a}}$ & $203.0 / 8.0^{\mathrm{a}}$ & $213.0 / 2.0^{\mathrm{b}}$ \\
Males (II) & $207.0 / 6.0^{\mathrm{c}}$ & $222.8 / 4.55^{\mathrm{d}}$ & $251.0 / 7.2^{\mathrm{e}}$ \\
\hline
\end{tabular}

Note: The results are expressed as medium/standard deviation. Different letters indicate significant differences $(P<0.05)$ according to Student-Newman-Keuls among days. the skin, respiratory, circulatory, autonomic and central nervous systems. No hair shedding, tremors, seizures, salivation, sedation, and drowsiness were observed. From the macroscopic point of view, no damage was seen in the samples of the selected organs (lung, heart, spleen, kidneys, and stomach), so it was decided not to carry out histopathological study. Then, the extract did not show toxicity in the assay conditions.

Wound healing activity

The hydroalcoholic extract was tested to measure its topical healing effect, at the dose of $100 \mathrm{mg} / \mathrm{kg}$ of body weight of the test animals. Table 2 lists the results of the evolution of healing $(\mathrm{mm})$ in the time. A reduction of the wound healing in the rats was observed after 3 days of the application of the extract. The group treated with the extract showed higher values than non-treated group, demonstrating their wound healing effect. On the other hand, the wound size of the rats treated with the extract and silver sulfadiazine cream showed similar values.

In addition, histopathological study in tissue samples from the wounds on the seventh day of treatment was carried out (Figure 3). At this time, the dermal reconstitution of the rats treated with silver sulfadiazine cream and hydroalcoholic extract of Guettarda calyptrata was highest than the non-treated rats, corroborating the results previously obtained.

Summarizing, the wound healing of the extract was demonstrated trough the measure of wound size and the histopathological analysis, corroborating the traditional use of the drug.

\section{Discussion}

The phytochemical evaluation is a crucial stage in the 
Table 2. Wound size by group and days in the healing trial

\begin{tabular}{|c|c|c|c|c|c|c|c|}
\hline \multirow{3}{*}{ Groups } & \multicolumn{7}{|c|}{ Wound size $(\mathrm{mm})$} \\
\hline & \multicolumn{7}{|c|}{ Days } \\
\hline & 1 & 2 & 3 & 4 & 5 & 6 & 7 \\
\hline No treatment & $10^{\mathrm{a}}$ & $10^{\mathrm{a}}$ & $9.7 / 0.5^{\mathrm{a}}$ & $9.7 / 0.50^{\mathrm{a}}$ & $9.0 / 0.8^{a}$ & $8.5 / 0.5^{a}$ & $7.5 / 0.5^{a}$ \\
\hline SSC & $10^{\mathrm{a}}$ & $10^{\mathrm{a}}$ & $6.2 / 1.3^{b}$ & $6.2 / 1.3^{b}$ & $5.4 / 0.5^{b}$ & $4.5 / 1.0^{b}$ & $4.0 / 1.0^{b}$ \\
\hline GCE & $10^{\mathrm{a}}$ & $10^{\mathrm{a}}$ & $7.2 / 1.8^{b}$ & $6.7 / 0.96^{b}$ & $5.5 / 0.5^{b}$ & $5.5 / 0.5^{b}$ & $5.0 / 0.8^{b}$ \\
\hline
\end{tabular}

Note: The results are expressed as medium/standard deviation. Different letters indicate significant differences $(P<0.05)$ according to StudentNewman-Keuls among groups. SSC: Silver Sulfadiazine cream, GCE: Guettarda calyptrata extract.

study of the chemical constituents of a plant. It includes from preliminary tests for the presence and quantification of different chemical groups of interest to the structural elucidation of said compounds (1). In the present investigation the phytochemical profile of G. calyptrata extract by phytochemical screening, TLC, HPLC and quantification of phenols and flavonoids was evaluated. Through phytochemical screening it was possible to detect various metabolites, including phenolic compounds, saponins, triterpenoids, and alkaloids, among other metabolites. The results are in correspondence with the studies carried out by Gutiérrez et al (7). and those referred for the genus Guettarda (17-20).

Regarding the chromatographic behavior of the extract (Figure 1), the presence of phenolic compounds and the flavonoids rutin and quercetin can be suggested, due to the behavior in terms of $\mathrm{Rf}$ and response to the development conditions used.

High-resolution liquid chromatography is a versatile and robust technique and in phytochemistry constitutes the main option for the study of fingerprints for the quality control of plant extracts (21). The analysis of the extract
(Figure 2C) allowed to observe two chromatographic peaks associated with rutin ( $\mathrm{RT}=22.10$ minutes) and quercetin ( $\mathrm{RT}=25.20$ minutes). The ultraviolet spectra (Figure 2D) registered absorption maxima at $257 \mathrm{~nm}$ and $356 \mathrm{~nm}$ (rutin) and $255 \mathrm{~nm}$ and $370 \mathrm{~nm}$ (quercetin), in correspondence with the literature (22). The HPLC study was performed for the first time for the species, providing the first findings on the fingerprint of the hydroalcoholic extract at $80 \%$ and the presence of rutin and quercetin in it.

The contents of total phenols and total flavonoids are in discrepancy with the studies carried out by Gutiérrez et al (7). on an aqueous extract where the concentration of said metabolites was lower $(2.83 \mathrm{mg} / \mathrm{mL}$, phenols and $1.14 \mathrm{mg} /$ $\mathrm{mL}$, flavonoids). The behavior could be associated with the type of solvent used for the extraction. The extraction of phenolic compounds and especially flavonoids is favored with ethanol, methanol and hydroalcoholic mixtures (23). Also, the plants were collected in different months that could also influence the variation of said metabolites. It is known that the production of active compounds in medicinal plants is strongly influenced by environmental

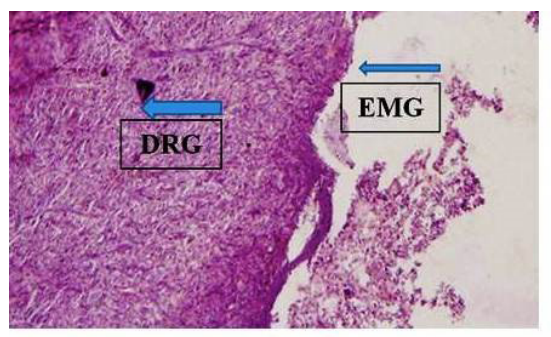

$\mathbf{A}$

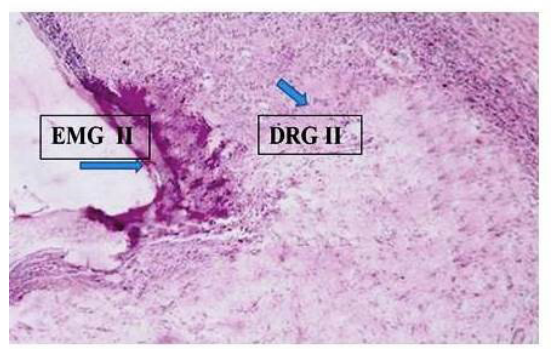

C

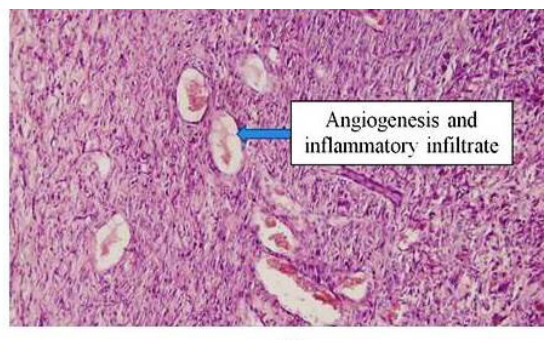

B

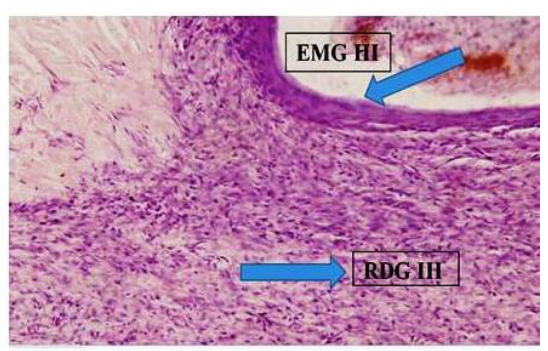

D

Figure 3. Histology of epidermis and dermis from the healing test. Hematoxylin-eosin stained. EMG: epithelial migration in degree; DRG: dermal reconstitution degree. (A) Control (10X magnification). (B) Control (20X magnification). (C) Silver Sulfadiazine (10X). (D) Hydroalcoholic extract of G. calyptrata (10X). 
factors (temperature, rainfall regime, etc.), which cause changes in the quantity and quality of their metabolites $(24,25)$.

An acute dermal toxicity test was executed, considering the traditional route of administration of the species. Weight gain was observed in the experimental animals, which suggested the absence of systemic toxic effects and the absence of organic damage (26).

The present study provides a scientific evaluation of the healing activity of a hydroalcoholic extract of $G$. calyptrata, tested at a dose of $100 \mathrm{mg} / \mathrm{kg}$ of body weight. During the development of the assay, the animals gained weight during the seven days of the experiment, in correspondence with the results of the toxicological study, indicating that the manipulation and application of the extract on the back of the rats does not produce damages that could alter the gain of body weight. From the third day, the size of the wounds began to decrease in animals treated with Silver Sulfadiazine and the extract, showing a similar behavior between them and significantly different compared to the group without treatment.

In the histopathological analysis it could be observed that the groups treated with the control drug (II) and the G. calyptrata extract (III) showed differences with respect to the group without treatment (I). In the samples corresponding to group I, scarce migration of the epithelial buds (EMG I) in the epidermis was observed, there was no contact between them and therefore the wound remained open, the scab remained, abundant inflammatory infiltrate of polymorphonuclear cells prevailed in the dermis and severe angiogenesis, with abundant new blood vessels and the presence of granulation tissue (DRG I). In group II, a migration of the epithelial buds that came into contact and close was observed, but the epithelium was thin, in some cases there was a permanent crust (MGE II) and in the dermis there was practically no angiogenesis, few fibroblasts, presence of disorganized collagen fibers (DRG II), which corresponds to an image of a closed wound. On the other hand, in group III, a complete migration of the epithelial buds was observed, closing the wound, with a thick epithelium (EMG III) and in the dermis few blood vessels and fibroblasts, and abundant well-organized collagen fibers (RDG III), which is in correspondence with a closed wound.

The histological study suggests that the extract stimulates healing due to re-epithelialization, a situation that is related to the migration of epidermal keratinocytes and the restoration of the basement membrane that delimits the epidermis from the dermis, which is also associated with deposition collagen levels and wound contraction compared to the untreated group (27).

Although on the seventh day after the end of the assay, from the macroscopic point of view the wounds treated with the extract did not close completely, when compared with the other two groups, the response was similar to that administered with Silver Sulfadiazine and there were differences with the untreated group, which had more open wounds than the treated groups, so it can be inferred that the G. calyptrata extract promotes the closure of open wounds according to the designed experimental model. However, it is suggested for future research to carry out other stains to determine the evidence of cellular elements involved in the healing process.

It is known that various phytochemicals such as flavonoids, saponins, tannins, terpenoids, especially polyphenols, promote wound healing activity, mainly due to their antioxidant, anti-inflammatory, antimicrobial, astringent properties, among others, which seem to be responsible for the closure of the wound and the improvement of epithelialization $(28,29)$. In the present work, these metabolites were identified in the extract, it was even possible to quantify phenols and flavonoids, and from the latter group the possible presence of rutin and quercetin was detected by HPLC. These metabolites could contribute, either individually or synergistically, to wound contraction and therefore to wound healing activity.

For example, quercetin stimulates the formation of extracellular matrix, regulates endothelial growth factor, and is transformative of the synthesis of growth factor (30,31). In addition, rutin improves production and accumulation of extracellular matrix in the wound healing process. It induces better neopithelium formation and thicker granulation, which is closer to the original epithelial tissue (32).

The results obtained so far make a valuable contribution to the study of the chemical composition of the species $G$. calyptrata that grows in Cuba, providing the first findings on the dermal safety of the plant and the demonstration of its healing effect. These studies contribute to justify the popular use of the plant and may contribute in the future to the development of herbal formulations with wound healing properties.

\section{Conclusion}

The presence of phenols compounds in the hydroalcoholic extract of the leaves of Guettarda calyptrata, its wound healing activity and the absence of acute dermal toxicity supporting the traditional use of the plant.

\section{Acknowledgement}

We are grateful to the Center for Research and Biological Evaluations, Institute of Pharmacy and Food, University of Havana, Cuba for the performance of the biological test.

\section{Authors' contributions}

YIG conceived and designed the experiment; JM, RS, LO, BAN and ZO performed the experiments; YG, RS and AF analyzed the data; YGI and AF wrote the paper. All authors read and confirmed publication of the paper. 


\section{Conflict of interests}

The authors declare no conflict of interest

\section{Ethical considerations}

This investigation followed the international regulations for animal care and was approved by Ethical Committee of the Center for Biological Investigations and Evaluations of the Institute of Pharmacy and Food of the University of Havana, Cuba (Agreement R-PI-2018-047; March 2018).

\section{Funding/Support}

None.

\section{References}

1. Cheuka PM, Mayoka G, Mutai P, Chibale K. The role of natural products in drug discovery and development against neglected tropical diseases. Molecules. 2016;22(1). doi: $10.3390 /$ molecules 22010058 .

2. Calixto JB. Efficacy, safety, quality control, marketing and regulatoryguidelinesfor herbalmedicines (phytotherapeutic agents). Braz J Med Biol Res. 2000;33(2):179-89. doi: 10.1590/s0100-879x2000000200004.

3. Saini S, Dhiman A, Nanda S. Traditional Indian medicinal plants with potential wound healing activity: a review. Int J Pharm Sci Res. 2016;7(5):1809-19. doi: 10.13040/ ijpsr.0975-8232.

4. Shedoeva A, Leavesley D, Upton Z, Fan C. Wound healing and the use of medicinal plants. Evid Based Complement Alternat Med. 2019;2019:2684108. doi: $10.1155 / 2019 / 2684108$.

5. Roig y Mesa JT. Plantas Medicinales, Aromáticas o Venenosas de Cuba. La Habana: Ciencia y Te囚cnica; 1974. p. 297.

6. Roig y Mesa JT. Diccionario Botánico de Nombres Vulgares Cubanos. 4th ed. La Habana: Ciencia y Te囚cnica; 2014. p. 295.

7. Gaitén YIG, Yaque JG, Lizama RS, Torres ZO, González AF, Jiménez JLM, et al. Pharmacognostical, phytochemical and antioxidant evaluations of Guettarda calyptrata A. Rich. Open Access Library Journal. 2018;5(10):1-10. doi: 10.4236/oalib.1104921.

8. Siddiqui S, Verma A, Rather AA, Jabeen F, Meghvansi MK. Preliminary phytochemicals analysis of some important medicinal and aromatic plants. Adv Biol Res. 2009;3:188195.

9. Chlopicka J, Pasko P, Gorinstein S, Jedryas A, Zagrodzki P. Total phenolic and total flavonoid content, antioxidant activity and sensory evaluation of pseudocereal breads. LWT Food Sci Technol. 2012;46(2):548-55. doi: 10.1016/j. lwt.2011.11.009.

10. Pourmorad F, Hosseinimerhr SJ, Shahabimajd N. Antioxidant activity, phenol and flavonoid contents of some selected Iranian medicinal plants. Afr J Biotechnol. 2006;5(11):1142-5.

11. Organisation for Economic Co-operation and Development (OECD). Test No. 402: Acute Dermal Toxicity, OECD Guidelines for the testing of Chemicals, Section 4. Paris: OECD; 2017. doi: 10.1787/9789264070585-en.

12. Berlanga J, Lodos J, Labarta V, Merino N, González T,
Hayes $\mathrm{O}$, et. al. The effect of the epidermal growth factor treatment schedule on the healing of full-thickness wounds in pigs. Biotecnol Apl. 1997;14(3):163-8.

13. McManus JFA, Mowry RW. Staining Methods: Histological and Histochemical. New York: Harper and Row; 1960. p. 423.

14. Price RD, Myers S, Leigh IM, Navsaria HA. The role of hyaluronic acid in wound healing: assessment of clinical evidence. Am J Clin Dermatol. 2005;6(6):393-402. doi: 10.2165/00128071-200506060-00006.

15. National Academy of Sciences USA. Guide for the Care and Use of Laboratory Animals. 8th ed. Washington, DC: National Academies Press; 2011. p. 246.

16. Rasul MG. Extraction, isolation and characterization of natural products from medicinal plants. Int J Basic Sci Appl Comput. 2018;2(6):1-6.

17. Capasso A, Balderrama L, Sivila SC, De Tommasi N, Sorrentino L, Pizza C. Phytochemical and pharmacological studies of Guettarda acreana. Planta Med. 1998;64(4):34852. doi: 10.1055/s-2006-957449.

18. Naressi MA, Manholer DD, Ames FQ, Bersani-Amado CA, Formagio ASN, Pereira ZV, et al. Chemical constituents, anti-inflammatory, and free-radical scavenging activities of Guettarda viburnoides Cham. \& Schltdl. (Rubiaceae). Quim Nova. 2015;38(7):932-6. doi: 10.5935/0100-4042.20150093.

19. Hussain MI, Syed QA, Khattak MNK, Hafez B, Reigosa MJ, El-Keblawy A. Natural product coumarins: biological and pharmacological perspectives. Biologia. 2019;74(7):863-88. doi: 10.2478/s11756-019-00242-x.

20. Revathi D, Rajeswari M. Wound healing activity of Guettarda speciosa Linn. Indo Am J Pharm Sci. 2018; 5(8):7896-903.

21. Fitzgerald $M$, Heinrich $M$, Booker A. Medicinal plant analysis: a historical and regional discussion of emergent complex techniques. Front Pharmacol. 2019;10:1480. doi: 10.3389/fphar.2019.01480.

22. Carbonaro M, Grant G. Absorption of quercetin and rutin in rat small intestine. Ann Nutr Metab. 2005;49(3):178-82. doi: $10.1159 / 000086882$.

23. Azmir J, Sarker MZI, Rahman MM, Sharif KM, Mohamed A, Sahena F, et al. Techniques for extraction of bioactive compounds from plant materials: a review. J Food Eng. 2013;117(4):426-36. doi: 10.1016/j.jfoodeng.2013.01.014.

24. Zargoosh Z, Ghavam M, Bacchetta G, Tavili A. Effects of ecological factors on the antioxidant potential and total phenol content of Scrophularia striata Boiss. Sci Rep. 2019;9(1):16021. doi: 10.1038/s41598-019-52605-8.

25. Yuan Y, Tang X, Jia Z, Li C, Ma J, Zhang J. The effects of ecological factors on the main medicinal components of Dendrobium officinale under different cultivation modes. Forests 2020;11(1):94. doi: 10.3390/f11010094.

26. Aular Y, Villamizar M, Pérez Y, Pérez V. Composición química y toxicidad aguda oral del aceite esencial de Lippia alba en ratones. Salus. 2016; 20(1):43-51

27. Boakye YD, Agyare C, Ayande GP, Titiloye N, Asiamah EA, Danquah KO. Assessment of wound-healing properties of medicinal plants: the case of Phyllanthus muellerianus. Front Pharmacol. 2018;9:945. doi: 10.3389/fphar.2018.00945.

28. Nurul I, Sok KW, Isa NM, Norazlina M, Kok-Yong C, Soelaiman IN, et al. Wound Healing Properties of Selected 
Natural Products. Int J Environ Res Public Health. 2018;15:2360. doi: 10.3390/ijerph15112360.

29. Demilew W, Adinew GM, Asrade S. Evaluation of the wound healing activity of the crude extract of leaves of Acanthus polystachyus Delile (Acanthaceae). Evid Based Complement Alternat Med. 2018;2018:2047896. doi: 10.1155/2018/2047896.

30. Doersch KM, Newell-Rogers MK. The impact of quercetin on wound healing relates to changes in $\alpha \mathrm{V}$ and $\beta 1$ integrin expression. Exp Biol Med. 2017;242(14):1424-31. doi:
$10.1177 / 1535370217712961$.

31. Taskan MM, Balci Yuce H, Karatas O, Gevrek F. Topical quercetin gel application improved wound healing in Wistar rats. Ann Med Res. 2019;26(10):2397-404. doi: 10.5455/annalsmedres.2019.05.289.

32. Aslam MS, Ahmad MS, Riaz H, Raza SA, Hussain S, Qureshi OS, et al. Role of flavonoids as wound healing agent. In: Phytochemicals - Source of Antioxidants and Role in Disease Prevention. IntechOpen; 2018. doi: 10.5772/ intechopen.79179. 